\title{
Cost-Effectiveness of Continuous Subcutaneous Insulin Infusion Versus Multiple Daily Injections in Patients with Poorly Controlled Type 2 Diabetes in Finland
}

\author{
Stephané Roze · Jayne Smith-Palmer (D) - Alexis Delbaere • \\ Karita Bjornstrom · Simona de Portu • William Valentine • \\ Mikko Honkasalo
}

Received: November 26, 2018 / Published online: February 7, 2019

(c) The Author(s) 2019

\section{ABSTRACT}

Introduction: Although primarily utilized in type 1 diabetes, continuous subcutaneous insulin infusion (CSII) represents a useful treatment alternative for patients with type 2 diabetes who are unable to achieve good glycemic control despite optimization of multiple daily injections (MDI). The aim of the analysis reported here was to investigate the long-term cost-effectiveness of CSII versus MDI in type 2 diabetes patients with poor glycemic control in Finland.

Enhanced Digital Features To view enhanced digital features for this article go to https://doi.org/10.6084/ m9.figshare.7614050.

S. Roze

HEVA HEOR, 186 Avenue Thiers, 69006 Lyon, France

J. Smith-Palmer $(\bowtie) \cdot$ W. Valentine

Ossian Health Economics and Communications,

Bäumleingasse 20, 4051 Basel, Switzerland

e-mail: Smith-palmer@ossianconsulting.com

A. Delbaere $\cdot$ S. de Portu

Medtronic International Sarl, Route du Molliau 31, 1131 Tolochenaz, Switzerland

K. Bjornstrom

Medtronic Finland, World Trade Center, Lentäjäntie

3, 01530 Vantaa, Finland

M. Honkasalo

Nurmijärvi Health Centre, Nurmijärvi, Finland
Methods: The IQVIA CORE Diabetes Model was used to make long-term projections of the clinical and economic outcomes associated with CSII use in type 2 diabetes, based on clinical input data from the OpT2mise trial, which showed that CSII was associated with a $1.1 \%$ decrease in glycated hemoglobin (HbA1c) in patients with poor glycemic control at baseline. The analysis was performed from a societal perspective and the time horizon was that of patient lifetimes. Future costs and clinical outcomes were discounted at 3\% per annum.

Results: Continuous subcutaneous insulin infusion was associated with a gain in qualityadjusted life expectancy of 0.32 quality-adjusted life-years (QALYs) compared with MDI (8.15 vs. 7.83 QALYs, respectively), as well as higher mean lifetime costs, resulting in an incremental cost-effectiveness ratio of Euro (EUR) 47,834 per QALY gained for CSII versus MDI. The higher treatment costs in the CSII group were partly mitigated by a $15 \%$ reduction in diabetes-related complication costs. Sensitivity analyses demonstrated that CSII was most cost-effective in patients with the highest baseline HbA1c values.

Conclusion: In Finland, CSII is likely to represent a cost-effective treatment alternative for patients with type 2 diabetes with poor glycemic control despite optimization of MDI. In such patients, CSII is associated with improved clinical outcomes relative to MDI, with the higher acquisition costs partly offset by a lower 
lifetime incidence and cost of diabetes-related complications.

Funding: Medtronic International Sàrl.

Keywords: Continuous subcutaneous insulin infusion; Cost-effectiveness; Finland; Type 2 diabetes

\section{INTRODUCTION}

In Finland the prevalence of type 2 diabetes has increased considerably in recent years, with figures from the Finnish Diabetes Association estimating that there are currently approximately 300,000 people diagnosed with type 2 diabetes in Finland with a further 150,000 people with undiagnosed diabetes [1]. This high, and increasing, prevalence means that the clinical and economic burden associated with the management of type 2 diabetes is both substantial and growing. The healthcare system in Finland provides universal coverage, although this is largely organized on a municipal rather than national level, resulting is some variation in resource allocation between different municipalities [2]. Treatment for diabetes (including insulin, insulin pens, insulin pumps and self-monitoring of blood glucose strips) is generally fully reimbursed in Finland [3], and it estimated that the management of diabetes and related complications now accounts for $12-15 \%$ of total healthcare spending in Finland $[4,5]$. Moreover, approximately $90 \%$ of the direct medical costs associated with diabetes are attributable to the management of diabetes-related complications, with annual direct costs for type 2 diabetes patients with diabetes-related complications being approximately 20-fold higher than for patients without complications [4]. Macrovascular complications in particular are the leading cause of morbidity and mortality in diabetes patients [5], and these complications account for a substantial proportion of overall healthcare resource utilization $[4,5]$. For example, in Finland in 2002 it was estimated that $25 \%$ of all myocardial infarctions and additionally $54-60 \%$ of all lower limb amputations occurred in people with diabetes [6].
One of the key risk factors for diabetes-related complications is poor glycemic control $[7,8]$; consequently, the management of blood glucose levels represents a fundamental component of diabetes management. However, as type 2 diabetes is a progressive disease, achieving glycemic control targets typically requires intensification of treatment as the disease progresses, with patients initiating insulin treatment when target glycated hemoglobin (HbA1c) levels can no longer be achieved with lifestyle modifications and oral antidiabetic (OAD) agents and/or glucagon-like peptide-1 receptor agonists. However, some patients on multiple daily injections (MDI) of insulin remain unable to achieve good glycemic control despite optimization of the insulin regimen [9]. For these patients continuous subcutaneous insulin infusion (CSII; insulin pump) may provide a solution in terms of achieving HbA1c targets.

CSII is frequently used in patients with type 1 diabetes, where it has been shown to improve glycemic control and reduce the risk for severe and nocturnal hypoglycemic events [10, 11]; however, the role of CSII in type 2 diabetes is less well established. The recently published OpT2mise trial was one of the first large-scale, randomized, controlled trials to assess the efficacy and safety of CSII in patients with type 2 diabetes who were unable to achieve good glycemic control despite optimization of MDI of a basal-bolus regimen [12, 13]. At baseline, mean daily basal (long-acting) insulin use in the MDI arm was $52 \mathrm{U} /$ day and the mean daily bolus (rapid-acting) insulin dose was $54 \mathrm{U} /$ day; the corresponding values in the CSII arm were 57 and $56 \mathrm{U} /$ day, respectively. Patients in the OpT2mise trial had a mean baseline HbA1c of $9.0 \%(75 \mathrm{mmol} / \mathrm{mol})$. At 6 months, CSII-treated patients had significantly greater improvements in glycemic control compared with those that remained on MDI (reduction of $1.1 \%$ for CSII vs. $0.4 \%$ for $\mathrm{MDI}$ ) as well demonstrating a clinically significant reduction in the amount of time spent in hyperglycemia [12]. Further, the improvement in $\mathrm{HbA1c}$ reported in the CSII group was also sustained through to 12 months [13]. Additionally, Finnish guidelines note that CSII is a treatment option for type 2 diabetes 
patients treated with insulin [5]. It is estimated that approximately $70 \%$ of patients on MDI regimens do not inject insulin outside of the home [14]. This in turn can influence glycemic control, with one study reporting that missing as few as two injections per week can increase the HbA1c level by $\geq 0.2 \%$ [15]. The flexibility provided by CSII may therefore offer benefits to patients who struggle to manage blood glucose levels with MDI. However, despite these potential benefits, higher initial acquisition costs and a requirement for training can represent barriers to CSII use in type 2 diabetes patients. Although different CSII devices are available from different manufacturers and there are differences in acquisition costs between different devices, the initial cost remains a barrier across all devices.

A long-term cost-effectiveness analysis enables evaluation of whether the higher treatment costs are mitigated by improved glycemic control and the resultant reduction in risk for long-term complications, which are frequently associated with high direct medical costs. As such, the aim of the current analysis was to investigate the long-term clinical and economic outcomes associated with the use of CSII [specifically the MiniMed $^{\mathrm{TM}}$ 640G device (Medtronic, Northridge, CA, USA)] compared with MDI in type 2 diabetes patients with poor baseline glycemic control in Finland.

\section{METHODS}

\section{Cost-Effectiveness Model Description}

The analysis was performed using the IQVIA CORE Diabetes Model ICDM (IQVIA, Basel, Switzerland), which is a validated long-term cost-effectiveness model that can be utilized for analyses of either type 1 or type 2 diabetes [16-18]. Structurally, it is based on a series of inter-dependent sub-models that simulate diabetes-related complications, including longterm cardiovascular, ophthalmic and renal complications; peripheral vascular disease, neuropathy and diabetic foot complications; and acute events, including hypoglycemic events. The sub-models have a semi-Markov structure and use time-, state-, time-in-stateand diabetes type-dependent probabilities derived from published literature to simulate disease progression. Monte Carlo simulation using tracker variables is used to overcome the memoryless properties of a standard Markov model and allows for interconnectivity and interaction between the different sub-models. For each model simulation a cohort of 1000 simulated patients was run through the model using first-order Monte Carlo simulation.

\section{Simulation Cohort and Treatment Effects}

Patient characteristics and treatment effects for the simulated cohort were sourced from the OpT2mise study (Table 1). Full details of the OpT2mise trial have been published by Reznik et al. [12]. In OpT2mise, at baseline, the mean (standard deviation; SD) age was 56 (9.6) years, mean (SD) duration of diabetes was 15 (8) years and the mean (SD) HbA1c at baseline was $9.0 \%$ $(0.75 \%)$ (75 [SD 8] $\mathrm{mmol} / \mathrm{mol})$. In terms of treatment effects, at month 6 of the OpT2mise

Table 1 Baseline cohort characteristics

\begin{tabular}{ll}
\hline Baseline cohort characteristics & Mean (SD) \\
\hline Age (years) & $56(9.6)$ \\
Male (\%) & 54.4 \\
Duration of diabetes (years) & $15(8)$ \\
HbAlc (\%) & $9.0(0.75)$ \\
Systolic blood pressure (mmHg) & $132(15)$ \\
Total cholesterol (mg/dL) & 172 \\
High-density lipoprotein (mg/dL) & 50 \\
Low-density lipoprotein (mg/dL) & 85 \\
Triglycerides (mg/dL) & 186 \\
Body mass index $\left(\mathrm{kg} / \mathrm{m}^{2}\right)$ & $33.4(7.25)$ \\
eGFR (mL/min/1.73 m $\left.{ }^{2}\right)$ & 77.5 \\
Smokers $(\%)$ & 15 \\
\hline $\begin{array}{l}\text { Source: Reznik et al. [12] } \\
\text { eGFR estimated glomerular filtration rate, } H b A 1 c \text { glycated } \\
\text { hemoglobin, } S D \text { standard deviation }\end{array}$ \\
\hline
\end{tabular}


trial, patients on CSII has a mean reduction from baseline in $\mathrm{HbA} 1 \mathrm{c}$ of $-1.1 \%$ compared with $-0.4 \%$ for patients in the MDI arm. Additionally, in the CSII arm there were no major hypoglycemic events compared with an event rate of 1.2 events per 100 patient-years in the MDI arm.

\section{Costs and Utilities}

In terms of intervention costs, only the incremental cost of CSII relative to MDI was included in the analysis (i.e. the cost difference between the CSII and MDI arms). Incremental treatment costs for the CSII arm included the acquisition cost of a MiniMed $640 \mathrm{G}^{\mathrm{TM}}$ insulin pump (Medtronic) and its consumables (infusion sets and reservoirs), as well as the cost of pump initiation training and the difference between the two arms in terms of insulin costs, as well as pens and needles. Direct medical costs for diabetes-related complications were sourced from published literature [19-21] (Table 2) and, where necessary, inflated to 2017 Euro (EUR) using the consumer price index from Statistics Finland [22]. Indirect costs associated with lost productivity were based on the human capital approach; age at first income, retirement age and average salaries were sourced from Statistics Finland [23]. In the absence of data specific to Finland, the duration of absenteeism from work owing to diabetes-related complications was sourced from a 2013 analysis from Denmark by Sørensen and Ploug [24]. Health state utility values (specific to patients with type 2 diabetes) for diabetes-related complications were sourced from a review by Beaudet et al. [25].

\section{Discount Rate, Time Horizon and Perspective}

The base case analysis was performed from the societal perspective (a sensitivity analysis was performed in which only direct costs were included). Future costs and clinical outcomes were discounted at a rate of $3 \%$ per annum in line with Finnish guidelines [26], and the time horizon of the analysis was that of patient lifetimes.

\section{Sensitivity Analysis}

A series of one-way sensitivity analyses were performed to determine the key drivers of outcomes. In particular, the influence of baseline HbA1c on outcomes was assessed by increasing and decreasing mean baseline HbA1c to $8.5 \%$ $(69 \mathrm{mmol} / \mathrm{mol})$ and $9.5 \% \quad(80 \mathrm{mmol} / \mathrm{mol})$, respectively (compared with $9.0 \%$ [75 mmol/ $\mathrm{mol}]$ in the base case analysis). The influence of the acquisition cost of CSII was assessed by performing analyses in which the cost of the pump, infusion set and reservoir were decreased by 10 and $20 \%$, respectively, and increased by $10 \%$. Allied to this, sensitivity analyses were performed in which the costs of diabetes-related complications were increased and decreased by $20 \%$ relative to the base case.

The influence of time horizon and discount rates on outcomes was also assessed. Sensitivity analyses were performed over time horizons of 5, 10 and 20 years, and analyses were run using discount rates of 0 and 5\% per annum.

\section{Compliance with Ethics Guidelines}

This article does not contain any studies with human participants or animals performed by any of the authors.

\section{RESULTS}

In the base case analysis, the use of CSII was associated with higher life expectancy and quality-adjusted life expectancy relative to MDI (Table 3). In the CSII group the projected mean quality adjusted life expectancy was 8.15 quality-adjusted life-years (QALYs) compared with 7.83 QALYs in the MDI group (difference of 0.32 QALYs). Similarly, discounted life expectancy was 0.34 years higher in the CSII arm than in the MDI arm (14.41 vs. 14.07 years, respectively). However, overall mean total lifetime costs were EUR 15,206 higher in the CSII group than in the MDI group (EUR 133,259 vs. EUR 118,053, respectively), resulting in an incremental cost-effectiveness ratio (ICER) of 
Table 2 Treatment/management costs for diabetes-related complications

\begin{tabular}{|c|c|c|}
\hline Event & Cost (in Euro) & References \\
\hline Myocardial infarction, year of event & 5187 & Sabale et al. [19] \\
\hline Myocardial infarction, subsequent years & 122 & Sabale et al. [19] \\
\hline Angina, first year & 3802 & Sabale et al. [19] \\
\hline Angina, subsequent years & 169 & Sabale et al. [19] \\
\hline Congestive heart failure, first year & 4186 & Sabale et al. [19] \\
\hline Congestive heart failure, subsequent years & 396 & Sabale et al. [19] \\
\hline Stroke, year of event & 6073 & Sabale et al. [19] \\
\hline Stroke, subsequent years & 256 & Sabale et al. [19] \\
\hline Stroke death within 30 days & 5907 & Sabale et al. [19] \\
\hline Peripheral vascular disease, annual & 3344 & DRG cost $[20]$ \\
\hline Hemodialysis, annual & 55,370 & Sabale et al. [19] \\
\hline Peritoneal dialysis, annual & 55,370 & Sabale et al. [19] \\
\hline Renal transplant, year of event & 57,770 & DRG cost $[20]$ \\
\hline Renal transplant, subsequent years & 1955 & DRG cost $[20]$ \\
\hline Major hypoglycemic event & 3374 & DRG cost $[20]$ \\
\hline Lactic acid event & 3405 & DRG cost $[20]$ \\
\hline Edema, onset & 2996 & DRG cost $[20]$ \\
\hline Edema, follow-up & 258 & DRG cost $[20]$ \\
\hline Photocoagulation & 2864 & DRG cost $[20]$ \\
\hline Cataract operation & 798 & DRG cost [20] \\
\hline Cataract follow-up & 445 & DRG cost $[20]$ \\
\hline Blindness, year of onset & 14,694 & Sabale et al. [19] \\
\hline Blindness, subsequent years & 469 & Schwarz et al. [21] \\
\hline Neuropathy, annual & 271 & DRG cost $[20]$ \\
\hline Amputation, event & 10,118 & Sabale et al. [19] \\
\hline Amputation prosthesis, event based & 10,118 & Sabale et al. [19] \\
\hline Gangrene treatment & 3854 & DRG cost $[20]$ \\
\hline After healed ulcer & 273 & DRG cost $[20]$ \\
\hline Infected ulcer & 2157 & DRG cost $[20]$ \\
\hline Standard uninfected ulcer & 273 & DRG cost $[20]$ \\
\hline Healed ulcer, history of amputation & 165 & Sabale et al. [19] \\
\hline
\end{tabular}

All costs are presented in 2017 Euro

$D R G$ Diagnosis-related group 
Table 3 Summary of base case results

\begin{tabular}{llll}
\hline Base case results & CSII arm & MDI arm & Difference \\
\hline Discounted life expectancy (years) & 14.41 & 14.07 & 0.34 \\
Quality-adjusted life expectancy (QALYs) & 8.15 & 7.83 & 0.32 \\
Total cost, direct and indirect (EUR) & 133,259 & 118,053 & 15,206 \\
Total cost, direct costs only (EUR) & 104,145 & 86,865 & 17,280 \\
Treatment & 52,518 & 26,425 & 26,093 \\
Management & 10,124 & 9935 & 189 \\
Cardiovascular disease & 8633 & 8743 & -110 \\
Renal disease & 12,053 & 17,829 & -5776 \\
Ulcer/amputation/neuropathy & 2705 & 2832 & -127 \\
Ophthalmic complications & 18,097 & 20,478 & -2381 \\
Hypoglycemia & 0 & 607 & -607 \\
Depression & 15 & 15 & 0 \\
ICER (EUR per QALY gained) & 47,834 & & \\
\hline
\end{tabular}

CSII continuous subcutaneous insulin infusion, ICER incremental cost-effectiveness ratio, $M D I$ multiple daily injections, QALY quality-adjusted life-year

EUR 47,834 per QALY gained for CSII versus MDI.

Higher total costs in the CSII arm were primarily driven by higher treatment costs associated with CSII use, with lifetime treatment costs being EUR 26,093 higher in the CSII arm than in MDI arm. However, this was partially offset by lower complication costs in the CSII arm; overall, over patient lifetimes mean complication costs were $15 \%$ lower in the CSII arm than in the MDI arm. In particular, mean total renal and ophthalmic complication costs were lower in the CSII arm compared with the MDI arm by more than EUR 5000 and EUR 2000, respectively. The lower complication costs in the CSII arm were driven by improved glycemic control leading to a delay in both the onset and lower cumulative incidence of diabetes-related complications in the CSII arm (Fig. 1). For example, the use of CSII was associated with mean delay in onset of $>1$ year for several complications, including retinopathy, proteinuria, neuropathy and macula edema.

The base case analysis included indirect costs associated with lost productivity; however, when only direct costs were included the ICER increased slightly to EUR 54,358 per QALY gained. The findings from other sensitivity analyses show that the cost-effectiveness of CSII was strongly associated with baseline HbA1c, the acquisition cost of CSII and the time horizon (Table 4). Sensitivity analyses around baseline HbA1c showed that CSII was most costeffective in those patients with the poorest glycemic control at baseline; in a scenario in which mean baseline HbA1c was increased to 9.5\% the ICER for CSII versus MDI decreased to EUR 25,555 per QALY gained. In contrast, if the mean baseline HbA1c was decreased to $8.5 \%$ the ICER increased to EUR 129,016 per QALY gained. Sensitivity analyses around the cost of CSII showed that, as anticipated, a 20\% reduction in CSII acquisition cost led to an ICER of EUR 23,420 per QALY gained while a 10\% increase in CSII cost resulted in the ICER increasing to EUR 60,041 per QALY gained. The results were also sensitive to changes in the time horizon of the analysis; over a short time horizon (5 years) the ICER increased to EUR 310,271 per QALY gained, likely due to the fact that the 


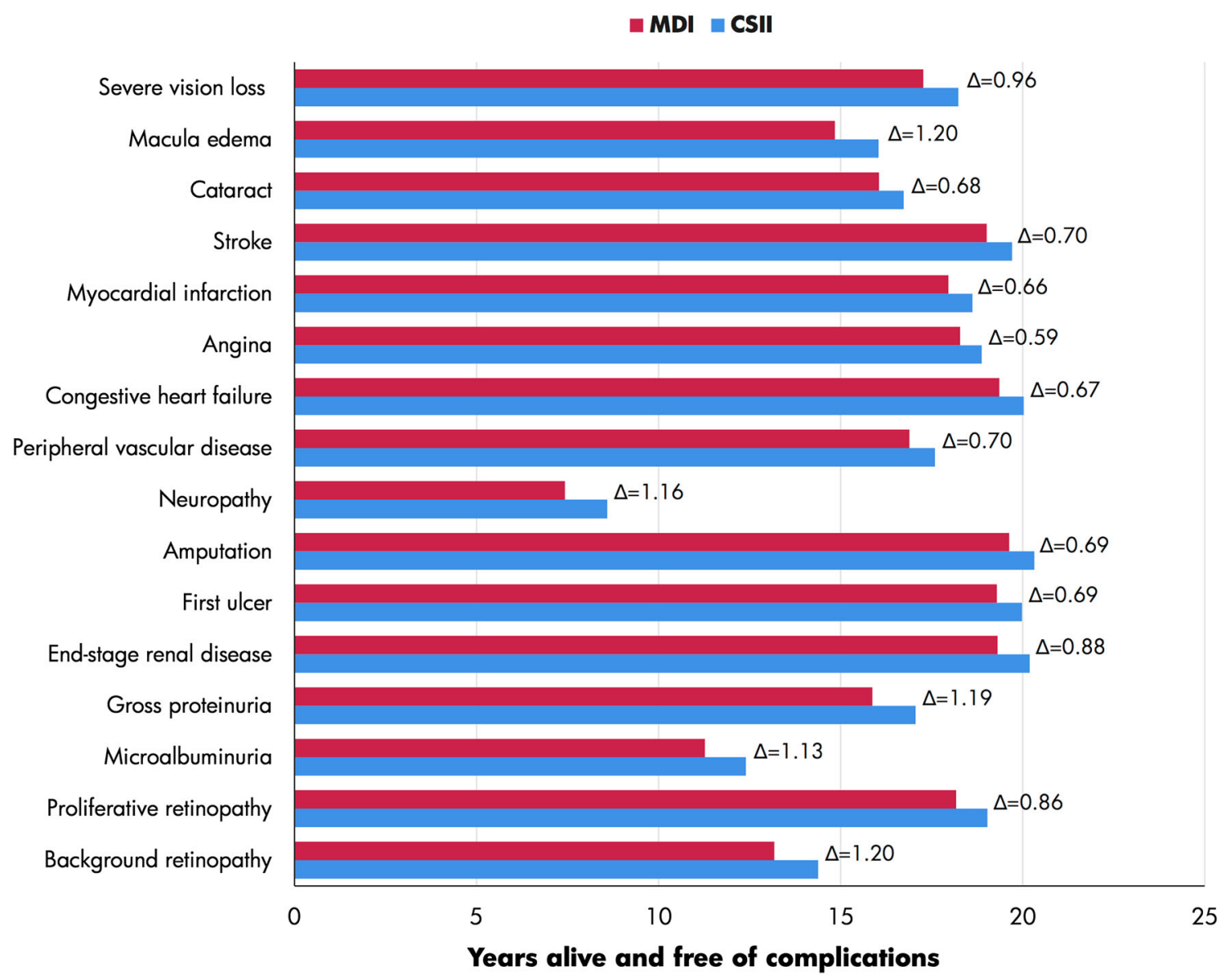

Fig. 1 Time alive and free of diabetes-related complications. CSII Continuous subcutaneous insulin infusion, MDI multiple daily injections

reduction in long-term complications associated with CSII use may not be apparent over such a short time horizon.

\section{DISCUSSION}

The results of the analysis suggest that, in Finland, for type 2 diabetes patients failing to achieve good glycemic control on MDI, switching to CSII is likely to be associated with improved clinical outcomes and over a longterm time horizon is likely to be cost-effective compared with remaining on MDI. In the base case analysis, the ICER for CSII versus MDI was below the commonly cited willingness-to-pay threshold of EUR 50,000 per QALY gained, suggesting that in the long-term, CSII would likely represent a cost-effective treatment option for patients with type 2 diabetes who cannot achieve good glycemic control on MDI. Moreover, sensitivity analyses demonstrated that long-term clinical and economic benefits were most pronounced in patients with the poorest glycemic control at baseline, with the ICER falling to below EUR 30,000 per QALY gained for patients with a baseline HbA1c of $9.5 \%$. This finding is in line with a recent post hoc analysis of 6-month data from the OpT2mise trial, which showed that higher baseline HbA1c was associated with a significantly greater reduction in HbA1c with CSII [27]. Additionally, although recent data are lacking, studies from 2004 to 2005 estimate that in Finland between 8 and 20\% of people with type 2 diabetes had a HbA1c $>9 \%$, although the 
Table 4 Summary findings of sensitivity analyses

\begin{tabular}{|c|c|c|c|c|c|}
\hline \multirow[t]{2}{*}{ Sensitivity analyses } & \multicolumn{2}{|l|}{ CSII arm } & \multicolumn{2}{|l|}{ MDI arm } & \multirow{2}{*}{$\begin{array}{l}\text { ICER (EUR per } \\
\text { QALY gained) }\end{array}$} \\
\hline & Total costs (EUR) & $\overline{\text { QALYs }}$ & Total costs (EUR) & $\overline{\text { QALYs }}$ & \\
\hline Base case & 133,259 & 8.151 & 118,053 & 7.833 & 47,834 \\
\hline Direct costs only & 104,145 & 8.151 & 86,865 & 7.833 & 54,358 \\
\hline CSII costs: $-20 \%$ & 125,498 & 8.151 & 118,053 & 7.833 & 23,420 \\
\hline CSII costs: $-10 \%$ & 129,379 & 8.151 & 118,053 & 7.833 & 35,627 \\
\hline CSII costs: $+10 \%$ & 137,140 & 8.151 & 118,053 & 7.833 & 60,041 \\
\hline Baseline HbA1c: $8.5 \%$ & 132,697 & 8.180 & 111,964 & 8.019 & 129,016 \\
\hline Baseline HbA1c: 9.5\% & 135,150 & 8.094 & 124,169 & 7.664 & 25,555 \\
\hline Complication costs: $+20 \%$ & 145,870 & 8.151 & 132,354 & 7.833 & 42,515 \\
\hline Complication costs: $-20 \%$ & 124,460 & 8.151 & 107,444 & 7.833 & 53,529 \\
\hline Time horizon: 5 years & 36,286 & 2.783 & 29,956 & 2.762 & 310,271 \\
\hline Time horizon: 10 years & 71,171 & 4.841 & 61,306 & 4.761 & 123,930 \\
\hline Time horizon: 20 years & 106,210 & 7.179 & 92,263 & 6.994 & 75,389 \\
\hline $0 \%$ per annum discount rate & 199,245 & 11.368 & 178,048 & 10.808 & 37,831 \\
\hline $5 \%$ per annum discount rate & 106,694 & 6.759 & 93,945 & 6.530 & 55,695 \\
\hline
\end{tabular}

$C S I I$ continuous subcutaneous insulin infusion, ICER incremental cost-effectiveness ratio, $M D I$ multiple daily injections, QALY quality-adjusted life years

proportion of poorly controlled patients on MDI versus those on OAD agents or lifestyle intervention alone is unknown [6]. Taken together, these findings suggest that insulintreated type 2 diabetes patients with HbA1c values of $\geq 9.5 \%$ would derive the greatest clinical benefit from switching to CSII and that this would be a cost-effective treatment modality from a payer perspective as well.

These findings largely concur with previous health economic analyses from the Netherlands and the USA. In the Netherlands, a 2016 analysis that also utilized clinical input data from the OpT2mise trial reported an ICER (from a third-party payer perspective) of EUR 62,895 per QALY gained [28]. Similarly, a real-world USAbased analysis from 2010 reported that for poorly controlled type 2 diabetes patients, total costs over a 4-year period were influenced by basal insulin dose at baseline and the effect of switching to CSII on the daily insulin dose. In patients with basal insulin use of $<100 \mathrm{U} /$ day at baseline, CSII was associated with an incremental cost of USD 5822 versus MDI over the 4 -year period. However, in those with baseline basal insulin use of $>150 \mathrm{U} /$ day, CSII was found to be cost-saving compared with MDI over 4 years [29].

Although the management of patients with type 2 diabetes is multifactorial, maintaining good glycemic control is a key component of disease management. It is well established that elevated HbA1c is a key risk factor for diabetesrelated complications and mortality [30, 31]. In this analysis, the improved glycemic control in the CSII arm relative to the MDI arm is therefore likely to have been a key driver of the projected lower cumulative incidence of complications in the CSII arm. In the OpT2mise trial the CSII arm experienced a $\mathrm{HbA1c}$ reduction of $-1.1 \%$ compared with $-0.4 \%$ for patients in the MDI arm. This treatment effect is consistent with the findings of earlier smaller trials as well as a recent meta-analysis of a total 
of five randomized controlled trials [32-35]. For example, in one small-scale study from France, type 2 diabetes patients with a mean baseline HbA1c of $9.0 \%(75 \mathrm{mmol} / \mathrm{mol})$ experienced a significantly greater improvement with CSII than with MDI $(p<0.03)$, with the magnitude of the treatment effect in terms of CSII similar to that reported in the OpT2mise trial [32]. Similarly, a 2017 meta-analysis, which included individual patient-level data from a total of 287 patients on MDI and 303 on CSII, showed that overall compared with MDI, CSII was associated with a HbA1c reduction of $0.4 \%$ $(4.4 \mathrm{mmol} / \mathrm{mol})$, although this treatment effect was much greater in patients with the poorest glycemic control at baseline [35]. This finding lends further weight to the hypothesis that those patients with the poorest glycemic control at baseline may represent the group that derives the largest clinical benefit from switching to CSII. The authors of the 2017 meta-analysis also report that across the five trials included in their meta-analysis CSII was associated with a $26 \%$ reduction in insulin dose, with the largest reduction being reported in those patients with the highest insulin doses at baseline [35]. In addition to data from clinical trials, USA-based data from routine clinical practice show that for type 2 diabetes patients who fail to achieve glycemic control by MDI, switching to CSII was associated with improved glycemic control in addition to a reduced incidence of emergency room visits and inpatient admissions [36, 37].

The current analysis is associated with limitations. In particular, long-term complication rates have been projected on the basis of the 6-month findings from a single clinical trial. However, long-term, large-scale data relating to the use of CSII in type 2 diabetes, either from clinical trials or real-world studies, are lacking, although data from a study in 102 patients in France showed that the treatment effect in terms of improved $\mathrm{HbA1c}$ persisted throughout 6 years of follow-up [38]. Nevertheless, the OpT2mise trial represents the largest trial of CSII in type 2 diabetes conducted to date and, therefore, despite the short-term nature of the trial, it is likely the most robust source of clinical evidence available for projecting long-term clinical and economic outcomes. Additionally, in the absence of data specific to Finland, it was necessary to utilize data from Denmark in relation to absenteeism related to diabetes-related complications. These data may not be fully generalizable to Finland owing to differences in social security or sickness benefit systems between settings.

\section{CONCLUSION}

The findings of this cost-effectiveness analysis, which is based on clinical input data from the OpT2mise trial, suggest that in Finland, CSII is likely to be cost-effective for patients unable to achieve good glycemic control on MDI. Further, our sensitivity analyses suggest that CSII is most cost-effective in those with the poorest glycemic control at baseline. The projected improvements in glycemic control with CSII were in turn projected to translate into a lower incidence of long-term diabetes-related complications, which partly offsets the higher treatment costs of CSII. As such, in Finland, based on a willingness-to-pay threshold of EUR 50,000 per QALY gained, switching to CSII using the MiniMed $^{\mathrm{TM}}$ 640G device is likely to be good value for money for type 2 diabetes patients on MDI with HbA1c levels of $>9.0 \%$.

\section{ACKNOWLEDGEMENTS}

Funding. Medtronic International Sàrl provided funding for the analysis and the article processing charges associated with the preparation of this manuscript. All authors had full access to all of the data in this study and take complete responsibility for the integrity of the data and accuracy of the data analysis.

Authorship. All named authors meet the International Committee of Medical Journal Editors (ICMJE) criteria for authorship for this article, take responsibility for the integrity of the work as a whole, and have given their approval for this version to be published. 
Disclosures. Stephané Roze is a current employee of HEVA HEOR, which has received fees from Medtronic International Sàrl in relation to the analysis presented here. Jayne Smith-Palmer is a current employee of Ossian Health Economics and Communications, which has received fees from Medtronic International Sàrl in relation to the analysis presented here. William Valentine is a current employee of Ossian Health Economics and Communications, which has received fees from Medtronic International Sàrl in relation to the analysis presented here.

Alexis Delbaere is a current or former employee of Medtronic International Sàrl. Simona de Portu is a current or former employee of Medtronic International Sàrl. Karita Bjornstrom is a current employee of Medtronic Finland. Mikko Honkasalo is a diabetologist who has been paid by Medtronic for a few lectures concerning insulin pump therapy and glucose sensoring. Mikko Honkasalo has taken part in ATTD congresses twice with funding from Medtronic to his working place. He also has participated in scientific education funded by Medtronic.

Compliance with Ethics Guidelines. This article does not contain any studies with human participants or animals performed by any of the authors.

Data Availability. The datasets during and/ or analyzed during the current study are available from the corresponding author on reasonable request.

Open Access. This article is distributed under the terms of the Creative Commons Attribution-NonCommercial 4.0 International License (http://creativecommons.org/licenses/ by-nc/4.0/), which permits any noncommercial use, distribution, and reproduction in any medium, provided you give appropriate credit to the original author(s) and the source, provide a link to the Creative Commons license, and indicate if changes were made.

\section{REFERENCES}

1. Finnish Diabetes Association. One out of ten has diabetes. https://www.diabetes.fi/en/finnish_diabet es_association/diabetes_in_finland. Last accessed 04 May 2018.

2. Teperi J, Porter ME, Vuorenkoski L, Baron JF. The Finnish HealthCare System: a value-based perspective. https://www.hbs.edu/faculty/Publication\%20 Files/Finnish_Health_Care_System_SITRA2009_785 84c8b10c4-4206-9f9a-441bf8be1a2c.pdf. Last accessed 07 Jan 2019.

3. Foundation of European Nurses in Diabetes, the International Diabetes Foundation and Primary Care Diabetes in Europe 2011. Diabetes the policy puzzle: is Europe making progress? https://ec. europa.eu/health/sites/health/files/major_chronic_ diseases/docs/policy_puzzle_2011.pdf. Last accessed 07 Jan 2019.

4. Niemi M, Winell K. Diabetes in Finland, prevalence and variation in quality of care. https://www. diabetes.fi/files/1105/Diabetes_in_Finland._Prevale nce_and_Variation_in_Quality_of_Care.pdf. Last accessed 04 May 2018.

5. The Finnish Medical Society Duodecim. Current care guidelines diabetes. http://www.kaypahoito.fi/web/ $\mathrm{kh} /$ suositukset/suositus?id=hoi50056\#s12. Last accessed 04 May 2018.

6. Winell K, Reunanen A. Diabetes barometer 2005. https://www.diabetes.fi/files/1106/Diabetesbaromet er_2005.pdf. Last accessed 08 Feb 2018.

7. Holman RR, Paul SK, Bethel MA, Matthews DR, Neil HA. 10-year follow-up of intensive glucose control in type 2 diabetes. N Engl J Med. 2008;359(15): 1577-89.

8. UK Prospective Diabetes Study (UKPDS) Group. Intensive blood-glucose control with sulphonylureas or insulin compared with conventional treatment and risk of complications in patients with type 2 diabetes (UKPDS 33). Lancet. 1998;352(9131):837-53 (Erratum in: Lancet 1999 Aug 14;354[9178]:602).

9. Riddle M, Umpierrez G, DiGenio A, Zhou R, Rosenstock J. Contributions of basal and postprandial hyperglycaemia over a wide range of A1C levels before and after treatment intensification in type 2 diabetes. Diabetes Care. 2011;34:2508-14.

10. Benkhadra K, Alahdab F, Tamhane SU, McCoy RG, Prokop LJ, Murad MH. Continuous subcutaneous insulin infusion versus multiple daily injections in individuals with type 1 diabetes: a systematic 
review and meta-analysis. Endocrine. 2017;55(1): 77-84.

11. Misso ML, Egberts KJ, Page M, O'Connor D, Shaw J. Continuous subcutaneous insulin infusion (CSII) versus multiple insulin injections for type 1 diabetes mellitus. Cochrane Database Syst Rev. 2010;1:CD005103.

12. Reznik Y, Cohen O, Aronson R, et al. Insulin pump treatment compared with multiple daily injections for treatment of type 2 diabetes (OpT2mise): a randomised open-label controlled trial. Lancet. 2014;384(9950):1265-72.

13. Aronson R, Reznik Y, Conget I, et al. Sustained efficacy of insulin pump therapy compared with multiple daily injections in type 2 diabetes: 12-month data from the OpT2mise randomized trial. Diabetes Obes Metab. 2016;18(5):500-7.

14. Bloomgarden ZT. Aspects of insulin treatment. Diabetes Care. 2010;33(1):e1-6.

15. Randløv J, Poulsen JU. How much do forgotten insulin injections matter to hemoglobin a1c in people with diabetes? A simulation study. J Diabetes Sci Technol. 2008;2(2):229-35.

16. Palmer AJ, Roze S, Valentine WJ, et al. The CORE Diabetes Model: projecting long-term clinical outcomes, costs and cost-effectiveness of interventions in diabetes mellitus (types 1 and 2) to support clinical and reimbursement decision-making. Curr Med Res Opin. 2004;20(Suppl 1):S5-26.

17. Palmer AJ, Roze S, Valentine WJ, et al. Validation of the CORE Diabetes Model against epidemiological and clinical studies. Curr Med Res Opin. 2004;20[Suppl 1]:S27-40.

18. McEwan P, Foos V, Palmer JL, Lamotte M, Lloyd A, Grant D. Validation of the IMS CORE Diabetes Model. Value Health. 2014;17(6):714-24.

19. Sabale U, Ekman M, Granström O, Bergenheim K, McEwan P. Cost-effectiveness of dapagliflozin (Forxiga $\AA$ ) added to metformin compared with sulfonylurea added to metformin in type 2 diabetes in the Nordic countries. Prim Care Diabetes. 2015;9(1):39-47.

20. Diagnosis-related group (DRG) cost. https://www. yliopistonapteekki.fi/. Last accessed 07 Feb 2018.

21. Schwarz B, Gouveia M, Chen J, et al. Cost-effectiveness of sitagliptin-based treatment regimens in European patients with type 2 diabetes and haemoglobin A1c above target on metformin monotherapy. Diabetes Obes Metab. 2008;10(Suppl 1):43-55.
22. Statistics Finland. Consumer price index. https:// www.stat.fi/til/khi/index_en.html. Last accessed 07 Feb 2018.

23. Statistics Finland. Wages, salaries and labour costs. http://tilastokeskus.fi/tup/suoluk/suoluk_palkat_en. html. Last accessed 07 Feb 2018.

24. Sørensen J, Ploug UJ. The cost of diabetes-related complications: registry-based analysis of days absent from work. Econ Res Int. 2013;2013:Article ID 618039 .

25. Beaudet A, Clegg J, Thuresson PO, Lloyd A, McEwan P. Review of utility values for economic modeling in type 2 diabetes. Value Health. 2014;17(4): 462-70.

26. Pharmaceutical Pricing Board (Lääkkeiden hintalautakunta). Application instructions health economic evaluation. 2017. http://www.hila.fi/c/ document_library/get_file?folderId=1133981\&name =DLFE-9844.pdf. Last accessed 06 Feb 2018.

27. Metzger M, Castañeda J, Reznik Y, et al. Factors associated with improved glycemic control following continuous subcutaneous insulin infusion therapy in patients with type 2 diabetes uncontrolled with bolus-basal insulin regimens: an analysis from the OpT2mise randomized trial. Diabetes Obes Metab. 2017;19(10):1490-4.

28. Roze S, Duteil E, Smith-Palmer J, et al. Cost effectiveness of continuous subcutaneous insulin infusion in people with type 2 diabetes in the Netherlands. J Med Econ. 2016;19(8):742-9.

29. Wolff-McDonagh P, Kaufmann J, Foreman S, Wisotsky S, Wisotsky JA, Wexler C. Using insulin pump therapy in poorly controlled type 2 diabetes. Diabetes Educ. 2010;36(4):657-65.

30. Stratton IM, Adler AI, Neil HA, et al. Association of glycaemia with macrovascular and microvascular complications of type 2 diabetes (UKPDS 35): prospective observational study. BMJ. 2000;321 (7258):405-12.

31. UK Prospective Diabetes Study (UKPDS) Group. Intensive blood-glucose control with sulphonylureas or insulin compared with conventional treatment and risk of complications in patients with type 2 diabetes (UKPDS 33). UK Prospective Diabetes Study (UKPDS) Group. Lancet. 1998;352 (9131):837-53.

32. Berthe E, Lireux B, Coffin C, et al. Effectiveness of intensive insulin therapy by multiple daily injections and continuous subcutaneous infusion: a comparison study in type 2 diabetes with conventional insulin regimen failure. Horm Metab Res. 2007;39(3):224-9. 
33. Noh YH, Lee SM, Kim EJ, et al. Improvement of cardiovascular risk factors in patients with type 2 diabetes after long-term continuous subcutaneous insulin infusion. Diabetes Metab Res Rev. 2008;24(5):384-91.

34. Frias JP, Bode BW, Bailey TS, Kipnes MS, Brunelle R, Edelman SV. A 16-week open-label, multicenter pilot study assessing insulin pump therapy in patients with type 2 diabetes suboptimally controlled with multiple daily injections. J Diabetes Sci Technol. 2011;5(4):887-93.

35. Pickup JC, Reznik Y, Sutton AJ. Glycemic control during continuous subcutaneous insulin infusion versus multiple daily insulin injections in type 2 diabetes: individual patient data meta-analysis and meta-regression of randomized controlled trials. Diabetes Care. 2017;40(5):715-22.
36. Lynch P, Riedel AA, Samant N, et al. Improved A1C by switching to continuous subcutaneous insulin infusion from injection insulin therapy in type 2 diabetes: a retrospective claims analysis. Prim Care Diabetes. 2010;4(4):209-14.

37. Lynch PM, Riedel AA, Samant N, et al. Resource utilization with insulin pump therapy for type 2 diabetes mellitus. Am J Manag Care. 2010;16(12): 892-6.

38. Reznik Y, Morera J, Rod A, et al. Efficacy of continuous subcutaneous insulin infusion in type 2 diabetes mellitus: a survey on a cohort of 102 patients with prolonged follow-up. Diabetes Technol Ther. 2010;12(12):931-6. 